\title{
Four-Element Triangular Wideband Dielectric Resonator Antenna excited by a Coaxial Probe
}

\author{
Amit Kumar, Utkarsh Besaria, Rajeev Gupta \\ Galgotias University, S R Group of Institution, MNNIT Allahabad
}

\begin{abstract}
This paper numerically examines an array of four dielectric resonant antenna of equilateral triangle shape. The Structure provides wideband low profile monopole-like antenna. As much as $30.90 \%$ matching bandwidth $\left(S_{11}<-10 \mathrm{~dB}\right)$ with monopole-like radiation pattern over the entire band has been achieved with 6.357 dBi peak gain. The geometry is a four equilateral triangular dielectric volume over a ground plane, and is centrally excited by a coaxial probe to provide a broadside radiation pattern. An approximate expression is used to compute the resonance frequency. Results are simulated using CST (Computer Simulation Technology) Microwave Studio Suite 10.
\end{abstract}

Keywords-Dielectric resonator $(D R)$, triangular dielectric resonator antenna (TDRA), $S_{11}$ (S-Parameter), perfect conductor (PEC), Impedance Bandwidth (IBW).

\section{Introduction}

Dielectric resonator has been used for energy storage for many years. Presently, DR has found its new application as a radiator in microwave circuits. Open dielectric resonators (DRs) offer attractive features as antenna elements [1]. Some features are small size, mechanical simplicity, high radiation efficiency (due to no inherent conductor loss), relatively large bandwidth, and simple coupling schemes to nearly all commonly used transmission lines. In addition it has the advantage of obtaining different radiation characteristics using different modes of the resonator [1-3]. The radiation Q factor of a DR antenna depends on its excitation modes as well as the dielectric constant of the ceramic material. The Q-factor increases and hence the bandwidth decreases with increasing dielectric constant and vice-versa. For this reason, DRs of relatively low dielectric constant are always used in antenna applications [4]. It was found that some geometry might have a wider bandwidth or better linear polarization characteristics than others. The advantage of the triangular DRA is that it offers a smaller area than either a cylindrical or rectangular DRA for a given height and resonant frequency. This paper presents the simulation of a four element Triangular wideband dielectric resonator antenna excited by a coaxial probe. The paper is organized as follows; Section II provides the basic theory of DRA. Details of the proposed antenna structure are provided in Section III. The simulation results of the proposed antenna structure have been presented and discussed in Section IV and finally, Section V provides Conclusions.

\section{Theory}

The triangular-shaped DRA, shown in Figure 1, has been introduced as a candidate for low-profile applications. As an example, a high-permittivity, low-profile triangular DRA was designed with $\varepsilon_{r}=82, \mathrm{~h}=1.1$ $\mathrm{mm}$ and $\mathrm{a}=20 \mathrm{~mm}$ [5]. This DRA was found to have a $5 \%$ IBW. To achieve the same resonant frequency, a cylindrical DRA of the same height and permittivity would require a radius of a $=7.55 \mathrm{~mm}$, while a rectangular DRA would require dimensions of $\mathrm{w}=\mathrm{d}=19 \mathrm{~mm}$. Thus the size of the triangular DRA would be about $92 \%$ that of the cylindrical DRA and about $48 \%$ that of the rectangular DRA. The resonant frequency of the $\mathrm{TM}_{l m n}$ modes of an equilateral triangular DRA (where $l+m+n=0$ ) can be estimated using the transcendental equations derived from a waveguide model [5]. The first subscript $l_{\text {in }}$ the notation $\mathrm{TM}_{l m n}$ states the order of the Bessel functions of the first and second kind which must be used to calculate the resonant frequency of that mode, the second subscript $m$ in the designation of the mode denotes the order of magnitude of the root which is used to calculate the resonant frequency, the third subscript $n$ is merely a coefficient in the argument of a trigonometric function which enters into the expressions for the electric and magnetic fields inside the cavity. The resonance frequency is predicted using a simple waveguide mode of a magnetic wall. Tangential field continuity to the surface of the dielectric interface at $\mathrm{z}= \pm \mathrm{h}$ will result in the transcendental equation [3].

$$
k_{z} \tan \left(k_{z} h-\frac{\pi}{2}\right)=k_{z}^{0} \text { And } k_{z}^{0}=\sqrt{\varepsilon_{r}-1-k_{z}} \ldots \text { (1) where }: k_{z}=\frac{p \pi}{2 h}, p=1,2,3 \ldots
$$

Where $k_{z}$ and $k_{z}^{0}$ are the wave numbers in the $z$-direction in the dielectric and free space, respectively. The dielectric resonator height $h$ can be obtained from (1) as [3] 


$$
h=\frac{1}{k_{z}}\left(\tan ^{-1}\left(\frac{k_{z}^{0}}{k_{z}}\right)+\frac{\pi}{2}\right) \ldots
$$

The resonance frequency can be obtained in terms of $k_{z}$, using the following expression:

$$
f_{m n}=\frac{c}{2 \pi \sqrt{\varepsilon_{r}}}\left[\left(\frac{4 \pi}{3 L_{d}}\right)^{2}\left(m^{2}+m n+n^{2}\right)+k_{z}^{2}\right]^{1 / 2} .
$$

Where $\mathrm{c}$ is the speed of light, $\mathrm{L}_{\mathrm{d}}$ is the length of the equal side of the equilateral triangular antenna and $\varepsilon_{r}$ is the dielectric constant. Here, we used the resonance frequency index $\mathrm{mn}$ instead of mnl because the third index $\mathrm{l}=\mathrm{m}+\mathrm{n}$ is dependent on the values of $\mathrm{m}$ and $\mathrm{n}$ [3]. It has been found that if we vary these parameters say the height of the antenna (h), dielectric constant of the DRA $\left(\varepsilon_{r}\right)$ and the side of the antenna $\left(\mathrm{L}_{\mathrm{d}}\right)$ as shown in equation (1-3) then we can find the combination of these parameters where we can have better radiation efficiency and bandwidth. Then we can calculate the resonant frequency at these specified values.

\section{Antenna Structure}

The geometry of the triangular dielectric resonator is shown in Fig. 1. A dielectric resonator with height hand an equitriangular uniform cross section with a side length $\mathrm{L}_{\mathrm{d}}$ is considered. The material used is Epoxy resin with dielectric constant $\varepsilon_{r}=4$, material density is $1500 \mathrm{~kg} / \mathrm{m}^{3}, \mu_{\mathrm{r}}=1$, thermal conductivity is $0.2 \mathrm{~W} / \mathrm{k} / \mathrm{m}$, Young's modulus $=13 \mathrm{Gpa}$ and Poisson's ratio $=0.45$. The excitation is a z-directed coaxial probe of length $\mathrm{h}_{\mathrm{P}}$ and located at the center. The probe is connected to an SMA connector. The ground plane is a square plane of a perfect conductor of side $\mathrm{S}$ and thickness $\mathrm{t}=3 \mathrm{~mm}$. Center probe feeding is done in this model.

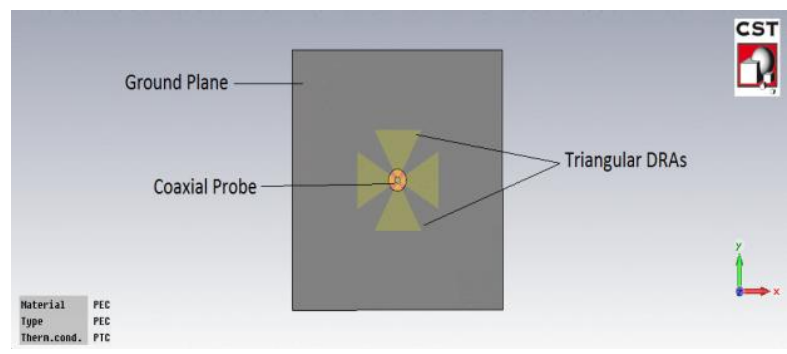

(a)

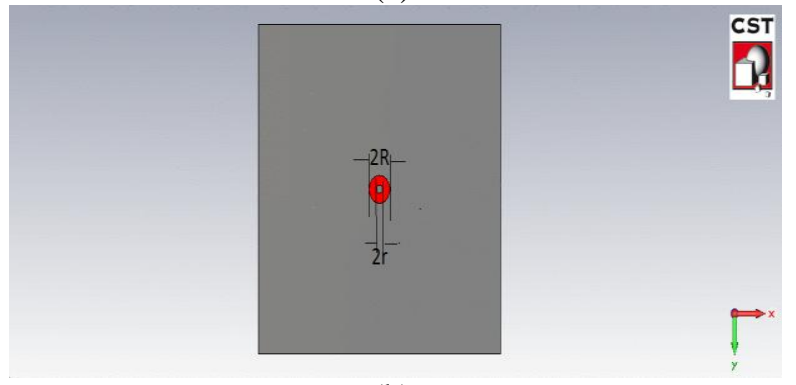

(b)

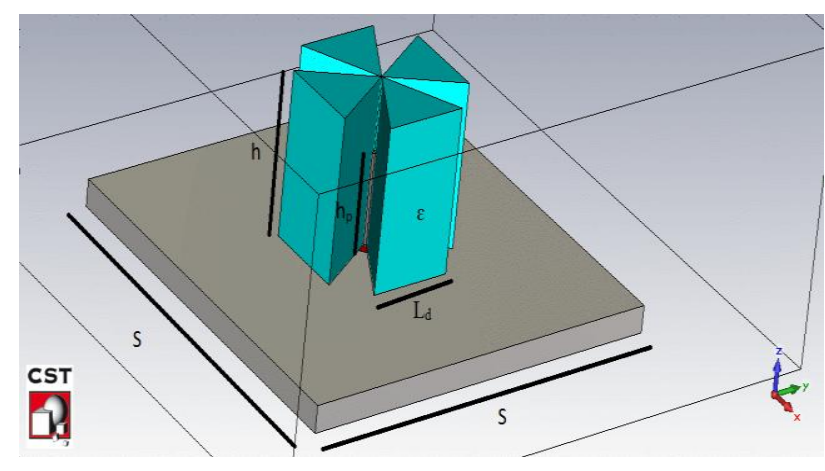

(c)

Figure 1. Geometry of the Four Triangular DRA with Ground Plane (a) Top View (b) Bottom view (c) Side View $\left[\mathrm{h}=18, \mathrm{hp}=10, \mathrm{~S}=50, \mathrm{~L}_{\mathrm{d}}=11, \varepsilon_{r}=4, \mathrm{r}=0.635, \mathrm{R}=2.124\right]$ All dimensions are in $\mathrm{mm}$ 
There is a ground plane as shown in Fig. 1(a) which is perfectly conductor. Then four equilateral triangular DRA are placed such that its one edge is touching in the center. Now center coaxial probe feeding is done whose radius is $\mathrm{r}=0.635 \mathrm{~mm}$ and is insulated by Teflon (material density is $2200 \mathrm{~kg} / \mathrm{m}^{3}, \mu_{\mathrm{r}}=1, \varepsilon_{r}=2.1$, thermal conductivity is $0.2 \mathrm{~W} / \mathrm{k} / \mathrm{m}$, Young's modulus=0.5 GPA, Thermal expansion coefficient $=1401 \mathrm{e}-6 / \mathrm{K}$ and Poisson's ratio=0.4) up to the ground plane whose outer radius is $\mathrm{R}=2.124 \mathrm{~mm}$ as shown in Fig. 1 (b). Fig. 1 (b) shows the bottom view of the antenna where we can see the coaxial probe insulated with Teflon at the center. And the Fig.1 (c) shows the side view of antenna to have a 3-d Visualization of the antenna that helps in understanding the antenna structure. The indicated ring in the Fig. 1 (b) is Teflon which is below the triangular DRA and around the probe to insulate it from the ground plane, so feeding can be done to triangular DRA not to the ground plane.

\section{Results}

The structure has been simulated and S-Parameter is shown in Fig. 2, we have a resonant frequency at $\mathrm{f}=5.21 \mathrm{GHz}$ with a bandwidth of $1.61 \mathrm{GHz}$ ranging from 4.47 to6.08 $\mathrm{GHz}$ (where $\mathrm{S}_{11}<-10 \mathrm{~dB}$ ). The return loss is maximum up to- $12.89 \mathrm{~dB}$ at the resonant frequency. The radiation-factor can be used to estimate the impedance bandwidth of a DRA [4]

Bandwidth $(B W)=\frac{V S W R-1}{Q_{\text {rad }} \sqrt{V S W R}}=\left(\frac{F H^{-F} L}{F C}\right) \ldots$ (4) Where $\mathrm{f}_{\mathrm{H}}$ is the higher cut-off frequency and $\mathrm{f}_{\mathrm{L}}$ is lower cut-off frequency. The return loss, $\mathrm{S}_{11} \mathrm{~dB}$ is shown in Fig. 2 where we can clearly see the maximum dip at $5.21 \mathrm{GHz}$.

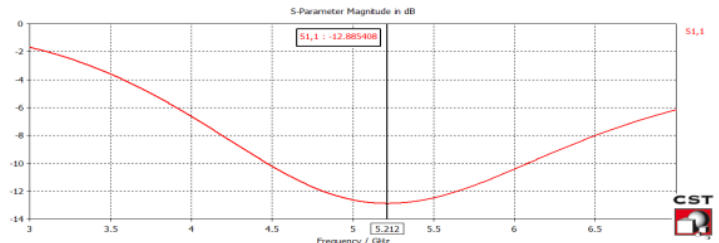

Figure 2. $\mathrm{S}$-parameter representation $\left[\mathrm{h}=18, \mathrm{hp}=10, \mathrm{~S}=50, \mathrm{~L}_{\mathrm{d}}=11, \varepsilon_{r}=4, \mathrm{r}=0.635, \mathrm{R}=2.124\right]$ All dimensions are in $\mathrm{mm}$

The Farfield radiation pattern at $\mathrm{f}=5.4 \mathrm{GHz}$ can be shown in Fig. 3 which shows a maximum gain of $6.357 \mathrm{dBi}$. We can have a polar plot of E-plane and H-plane in Fig. 4(a), (b) respectively to understand the variation with change in Theta and Phi. E-Plane is representing Electric Monopole structure created as it is centrally excited and only one mode is excited. Its main lobe direction is $90.0 \mathrm{deg}$. and its magnitude is $6.4 \mathrm{~dB}$. $\mathrm{H}$-Plane is representing Horizontal Magnetic Dipole whose main lobe direction is $0.0 \mathrm{deg}$. and its magnitude is 82.8 dB. In Fig. 5 we can see the E - field distribution which is converging at the center. Fig. 6 shows the circularly revolving $\mathrm{H}$ - field.

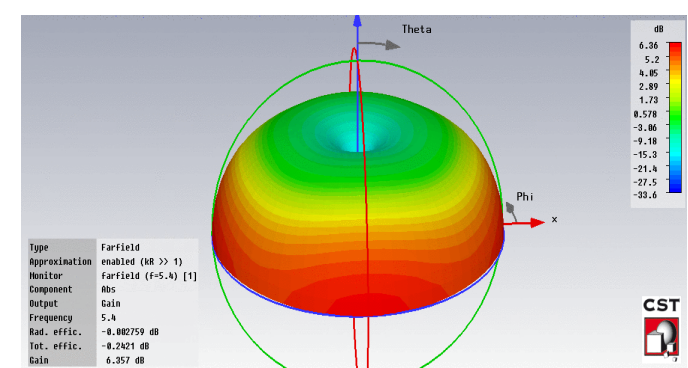

Figure 3.3-D view simulated gain of the triangular dielectric resonator $\left[\mathrm{h}=18, \mathrm{hp}=10, \mathrm{~S}=50, \mathrm{~L}_{\mathrm{d}}=11, \varepsilon_{r}=4\right.$, $\mathrm{r}=0.635, \mathrm{R}=2.124$ ] All dimensions are in $\mathrm{mm}$

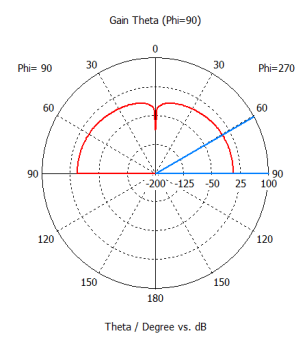

(a)

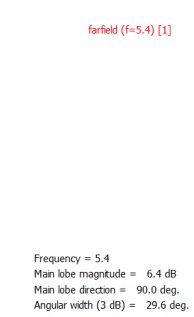

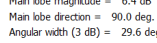



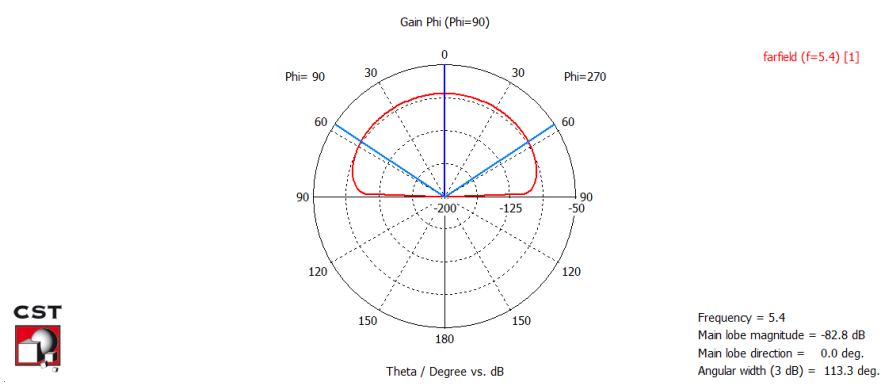

(b)

Figure 4. (a)E-Plane (Electric Monopole), (b) H-Plane (Horizontal Magnetic Dipole) $[\mathrm{h}=18, \mathrm{hp}=10, \mathrm{~S}=50$, $\left.\mathrm{L}_{\mathrm{d}}=11, \varepsilon_{r}=4, \mathrm{r}=0.635, \mathrm{R}=2.124\right]$ All dimensions are in $\mathrm{mm}$

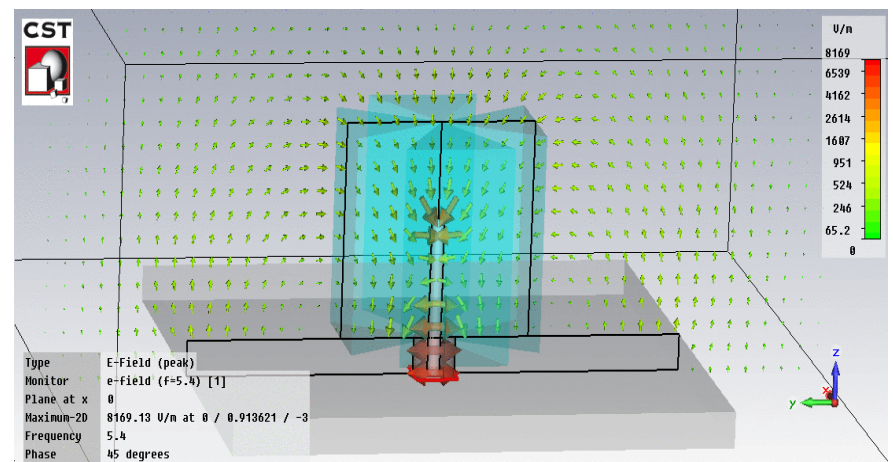

Figure 5.E-Fielddistribution at $5.4 \mathrm{GHz}\left[\mathrm{h}=18, \mathrm{hp}=10, \mathrm{~S}=50, \mathrm{~L}_{\mathrm{d}}=11, \varepsilon_{r}=4, \mathrm{r}=0.635, \mathrm{R}=2.124\right]$ All dimensions are in $\mathrm{mm}$

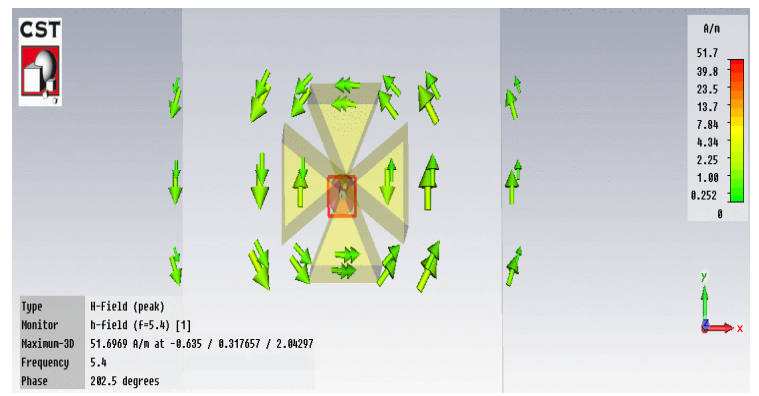

Figure 6. H-Field distribution at $5.4 \mathrm{GHz}\left[\mathrm{h}=18, \mathrm{hp}=10, \mathrm{~S}=50, \mathrm{~L}_{\mathrm{d}}=11, \varepsilon_{r}=4, \mathrm{r}=0.635, \mathrm{R}=2.124\right]$ All dimensions are in $\mathrm{mm}$

Fig. 7 shows the variation in the real $\left(\mathrm{R}_{\mathrm{in}}\right)$ and imaginary part $\left(\mathrm{X}_{\mathrm{in}}\right)$ of simulated input impedance. When there is a proper impedance matching then we get the resonant frequency where the gain is maximized.

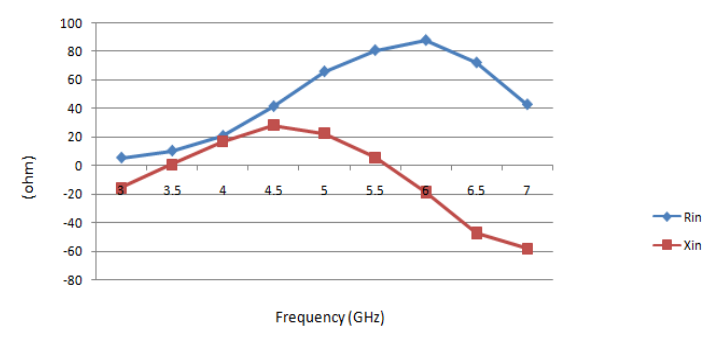

Figure 7. Simulated input impedance $\left[\mathrm{h}=18, \mathrm{hp}=10, \mathrm{~S}=50, \mathrm{~L}_{\mathrm{d}}=11, \varepsilon_{r}=4, \mathrm{r}=0.635, \mathrm{R}=2.124\right]$ All dimensions are in $\mathrm{mm}$

Fig. 8 and Table I shows IBW is maximized (30.90\%) for $\varepsilon_{r}=4$ keeping other parameters constant. As we increase $\varepsilon_{r}$, IBW will go on decreasing as the Q-factor is directly proportional $\varepsilon_{r}$ and hence inversely proportional to IBW as shown in equation (4). Similarly, in Fig. 9 and Table II represents IBW is maximum for height of antenna $\mathrm{h}=18 \mathrm{~mm}$ by keeping other parameters constant. 


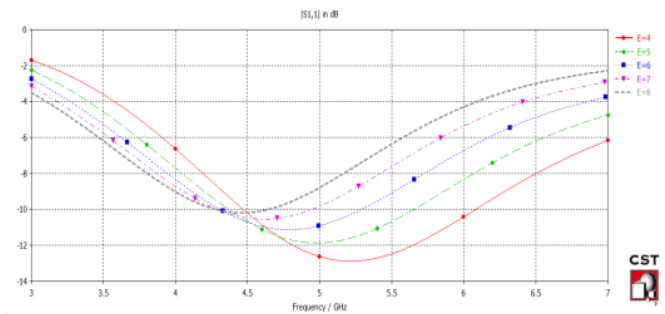

Figure 8. Variation of S-Parameter with variation in $\varepsilon_{r} \quad\left[\mathrm{~h}=18, \mathrm{hp}=10, \mathrm{~S}=50, \mathrm{~L}_{\mathrm{d}}=11, \mathrm{r}=0.635, \mathrm{R}=2.124\right]$ All dimensions are in $\mathrm{mm}$

Table I. IMPEDANCE BANDWIDTH FOR DIFFERENT DIELECTRIC CONSTANT $[\mathrm{h}=18, \mathrm{hp}=10, \mathrm{~S}=50$, $\left.\mathrm{L}_{\mathrm{d}}=11, \mathrm{r}=0.635, \mathrm{R}=2.124\right]$ All Frequency are in $\mathrm{GHz}$

\begin{tabular}{|c|c|c|c|c|}
\hline Epsilon $\left(\varepsilon_{\mathrm{r}}\right)$ & Range $\left(f_{H^{-}}-f_{L}\right)$ & $\begin{array}{c}\text { Resonant Frequency } \\
\left(\mathrm{f}_{\mathrm{C}}\right)\end{array}$ & BW & Impedance BW $\left(\frac{\mathrm{fH}-\mathrm{fL}}{\mathrm{fC}}\right) \%$ \\
\hline 4 & $6.08-4.47$ & 5.21 & 1.61 & 30.90 \\
\hline 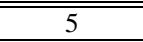 & $5.65-4.37$ & 4.98 & 1.28 & 25.70 \\
\hline 6 & $5.29-4.31$ & 4.78 & 0.98 & 20.50 \\
\hline$\overline{77}$ & $4.94-4.29$ & "4.61 & 0.65 & "14.10 \\
\hline 8 & $4.64-4.28$ & 4.46 & 0.36 & 08.07 \\
\hline
\end{tabular}

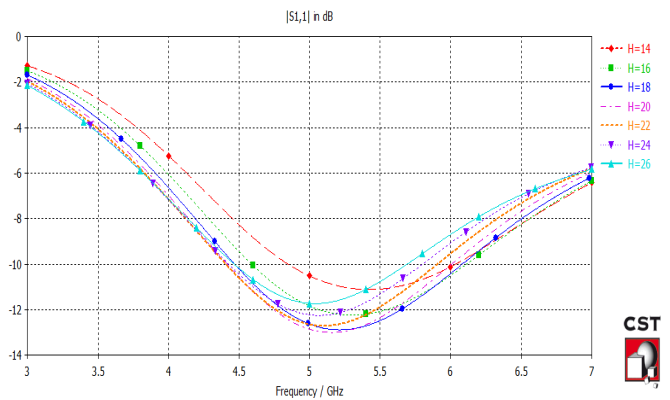

Figure 9. Variation of $\mathrm{S}$-Parameter with variation in $\mathrm{h}$ with $\left[\mathrm{hp}=10, \mathrm{~S}=50, \mathrm{~L}_{\mathrm{d}}=11, \varepsilon_{r}=4, \mathrm{r}=0.635, \mathrm{R}=2.124\right]$ All dimensions are in $\mathrm{mm}$

Table II. IMPEDANCE BANDWIDTHFOR DIFFERENT HEIGHT OF ANTENNA [ $h p=10, \mathrm{~S}=50, \mathrm{~L}_{\mathrm{d}}=11$, $\left.\varepsilon_{r}=4, \mathrm{r}=0.635, \mathrm{R}=2.124\right]$ All Frequency are in $\mathrm{GHz}$

\begin{tabular}{|c||c||c||c||c||}
\hline $\begin{array}{l}\text { Height of } \\
\text { antenna (h) }\end{array}$ & Range $\left(\mathrm{f}_{\mathrm{H}}-\mathrm{f}_{\mathrm{L}}\right)$ & $\begin{array}{c}\text { Resonant } \\
\text { Frequency } \\
\left(\mathrm{f}_{\mathrm{C}}\right)\end{array}$ & $\mathrm{BW}$ & $\begin{array}{c}\text { Impedance } \\
\mathrm{BW} \\
\left(\frac{\mathrm{fH}-\mathrm{fL}}{\mathrm{fC}}\right) \%\end{array}$ \\
\hline \hline 14 & $6.01-4.84$ & 5.42 & 1.17 & 21.57 \\
\hline \hline 16 & $6.11-4.59$ & 5.30 & 1.52 & 28.68 \\
\hline \hline 18 & $6.08-4.47$ & 5.21 & 1.61 & 30.90 \\
\hline \hline 20 & $6.00-4.42$ & 5.15 & 1.58 & 30.67 \\
\hline \hline 22 & $5.90-4.41$ & 5.10 & 1.49 & 29.21 \\
\hline \hline 24 & $5.79-4.42$ & 5.07 & 1.37 & 27.02 \\
\hline \hline 26 & $5.69-4.47$ & 5.04 & 1.22 & 24.21 \\
\hline
\end{tabular}

Here, the diameter of the probe is $2 \mathrm{r}=1.27 \mathrm{~mm}$ and its height $\left(\mathrm{h}_{\mathrm{P}}\right)$ is varied accordingly for proper matching. Fig. 10 and Table III shows IBW is maximum for $h_{P}=10 \mathrm{~mm}$.

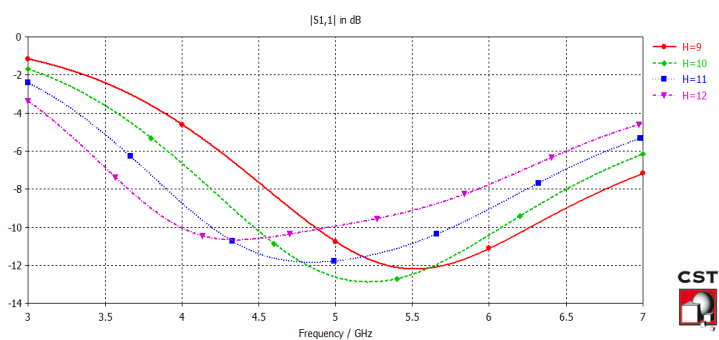

Figure 10. Variation of S-Parameter with variation in hip [ $\left.h=18, \mathrm{~S}=50, \mathrm{~L}_{\mathrm{d}}=11, \varepsilon_{r}=4, \mathrm{r}=0.635, \mathrm{R}=2.124\right]$ All dimensions are in $\mathrm{mm}$. 
Table III. IMPEDANCE BANDWIDTH FOR DIFFERENT HEIGHT OF COAXIAL PROBE $\mathrm{h}=18, \mathrm{~S}=50$, $\left.\mathrm{L}_{\mathrm{d}}=11, \varepsilon_{r}=4, \mathrm{r}=0.635, \mathrm{R}=2.124\right]$ All Frequency are in $\mathrm{GHz}$

\begin{tabular}{|c|c|c|c|c|}
\hline $\begin{array}{l}\text { Height of } \\
\text { Coaxial } \\
\text { Cable (hp) }\end{array}$ & $\operatorname{Range}\left(\mathrm{f}_{\mathrm{H}^{-}}-\mathrm{f}_{\mathrm{L}}\right)$ & $\begin{array}{c}\text { Resonant } \\
\text { Frequency }\left(\mathrm{f}_{\mathrm{C}}\right)\end{array}$ & BW & $\begin{array}{c}\text { Impedanc } \\
\text { e BW } \\
\left(\frac{\mathrm{fH}-\mathrm{fL}}{\mathrm{fC}}\right) \%\end{array}$ \\
\hline 9 & $6.26-4.86$ & 5.52 & 1.40 & 25.36 \\
\hline 10 & $6.08-4.47$ & 5.21 & 1.61 & 30.90 \\
\hline 11 & $5.75-4.20$ & 4.84 & 1.55 & 32.02 \\
\hline 12 & $5.01-4.00$ & 4.35 & 1.01 & 23.22 \\
\hline
\end{tabular}

It has been observed that we get better results for $\mathrm{h}=18 \mathrm{~mm}, \mathrm{~h}_{\mathrm{P}}=10 \mathrm{~mm}, \varepsilon_{r}=4$.

The simulated VSWR of Four TDRA is shown in Fig. 11. The matching frequency range is from 4.47 to 6.08 $\mathrm{GHz}$ where the VSWR $<2$ and return loss $\left(\mathrm{S}_{11}\right)<-10 \mathrm{~dB}$.

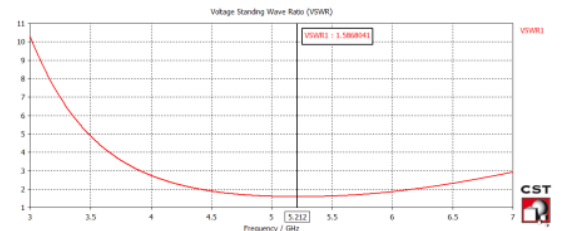

Figure 11.VSWR for Four Triangular DRAs $\left[\mathrm{h}=18, \mathrm{hp}=10, \mathrm{~S}=50, \mathrm{~L}_{\mathrm{d}}=11, \varepsilon_{r}=4, \mathrm{r}=0.635, \mathrm{R}=2.124\right]$ All dimensions are in $\mathrm{mm}$

This can be examined through these formulae

$\Gamma=\left(\mathrm{Z}_{1}-\mathrm{Z}_{\mathrm{o}}\right) /\left(\mathrm{Z}_{1}+\mathrm{Z}_{\mathrm{o}}\right) \ldots(5)$

$\operatorname{VSWR}=(1+\Gamma) /(1-\Gamma) \ldots(6)$

Where $\Gamma$ is the reflection co-efficient. $Z_{1}$ is the antenna impedance and $Z_{0}$ is the feed line impedance.

\section{Conclusions}

This paper examined the performance of the TDRA excited by a coaxial probe. The resonance frequencies were computed using an approximate expression. The selected mode was verified using $\mathrm{H}$-field pattern. It is found that the proposed TDRA has a wideband pattern as it has IBW $30.90 \%$ (> $20 \%$ ) where $\mathrm{S}_{11}<$ $-10 \mathrm{~dB}$ from 4.47 to $6.08 \mathrm{GHz}$. It has a monopole like radiation pattern which is stable in the pass band with gain $6.357 \mathrm{dBi}$ at $5.4 \mathrm{GHz}$. This antenna may be suitable for C-band application like IEEE 802.11a Wi-Fi and cordless telephone.

\section{References}

[1] J. K. Plourde and C. Ren, MEMBER, IEEE “Application of Dielectric Resonators in Microwave Components,"IEEE Transactions on Microwave Theory and Techniques, vol. MTT-29, NO. 8, pp. 754-770, AUGUST 1981.

[2] R. K. Mongia and P. Bhartia, "Dielectric resonator antennas-A review and general design relations for resonant frequency and bandwidth,"International Journal of Microwave and Millimeter-Wave Computer Aided Engineering, vol. 4, pp. 230-247, July 1994.

[3] A. A. Kiosk, "A Triangular dielectric resonator Antenna Excited by a coaxial probe,"Microwave and Optical Technology Letters / Vol. 30, No. 5, pp. 340-341, September 52001.

[4] R. K. Chaudhary, K. V. Srivastava and A. Biswas, "Four Element Multilayer Cylindrical Dielectric Resonator Antenna Excited by coaxial probe,"IEEE 978-1-61284-091-8/11/2011.

[5] Lo, H.Y. and K. W. Leung, "Excitation of low -Profile Equilateral- Triangle Dielectric Resonator Antenna Using a Conducting Conformal Strip," Microwave and Optical Technology Letters, Vol. 29, NO. 5, pp. 317-319, June 2001.

[6] Yoshihiko Akaiwa, "Operation Modes of a Waveguide Y Circulator," IEEE Transactions on Microwave Theory \& Techniques, pp. 954-960, November 1974.

[7] H.Y. Lo, K. W. Leung, K.M. Luk, and E.K.N. Yung, "Low profile triangular dielectric resonator antenna,"2000 IEEE Antennas and Propagation Society International Symposium, Vol. 4, pp. 2088-2091, July 2000.

[8] S. A. Long, M. W. McAllister and L.C. Shen, "The resonant cylindrical dielectric cavity antenna,"IEEE Transactions on Antennas Propagation, pp. 406-412, April 1983.

[9] M. C. McAllister, G.L. Conway and S. A. Long, "Rectangular dielectric-resonator antenna,"Electron Letter, pp. 218-219, March 1983.

[10] A. A. Kishk, G. Zhou, and A. W. Glisson, "Analysis of dielectric resonator antennas with emphasis on hemispherical structures,"IEEE Antennas and Propagation Magazine, Vol. 36, No. 2, pp. 20-31,April 1994.

[11] R. K. Mongia, A. Ittipiboon, P. Bhartia, and M. Cuhaci, "Electric monopole antenna using a dielectric ring resonator,"Electron Letter, 1530-1531, August 1993.

[12] B. Owen, "The identification of modal resonances in ferrite loaded waveguide Y-junctions and their adjustment for circulation," Bell System Tech. J., Vol. 51, pp. 595-627, March 1972.

[13] J. Helszajn and F. C. Tan, "Design data for radial-waveguide circulators using partial-height ferrite resonators," IEEE Trans. Microwave Theory Tech., Vol. MTT-23, pp. 288-298, March1975.

[14] K. K. Chow, "On the solution and field pattern of cylindrical and dielectric resonators," IEEE Transaction on Microwave Theory and Techniques, vol. MTT-14, pp. 439, September 1996.

[15] D. Guha and Y. M. M. Antar, "Four-Element Cylindrical Dielectric Resonator Antenna for Wideband Monopole-Like Radiation,"IEEE Transaction on Antennas and Propagation, Vol.54, No.9, pp. 2657-2662, September 2006. 